\title{
Barriers Related to Mask Wearing in African American Neighborhood Businesses
}

\author{
Holly J. Jones ${ }^{1,2}\left(\mathbb{D} \cdot\right.$ Regina Hutchins $^{2} \cdot$ Peggy Brown $^{2} \cdot$ Sheeva Crute $^{2} \cdot$ Linda Ntumba $^{2} \cdot$ Carolyn Ward $^{2}$
}

Accepted: 25 March 2021 / Published online: 3 April 2021

(c) The Author(s), under exclusive licence to Springer Science+Business Media, LLC, part of Springer Nature 2021

\begin{abstract}
African Americans and people of color have been disproportionately affected by the coronavirus (COVID-19) pandemic. As the second wave of the virus raged across the nation, there was a renewed effort to increase adherence to social distancing and mask-wearing guidelines. A community-based study led by members of the local National Black Nurses Association (NBNA) was conducted in a Midwest metropolitan city to identify barriers to mask-wearing experienced by business owners and employees in predominantly African American neighborhoods. Neighborhood business owners and their employees are essential to the life of a community as they provide needed goods and services from convenient neighborhood locations. Thus, attitudes and behaviors exhibited by business owners, supervisors, and other employees are important to combat COVID-19 in underserved communities. Semi-structured interviews were conducted with 39 business owners or supervising employees. Simple content analysis was used to identify codes and themes from the narrative data. Responses to the question 'What can make mask-wearing easier for your business and businesses in the neighborhood?' yielded three themes. Themes included 'a sense of community', the 'need for external support', and 'internal leadership'. These themes can be used to develop interventions to improve mask-wearing behaviors, support business owners and their customers, and lower the spread of COVID-19 in high-risk communities.
\end{abstract}

Keywords Community health · Mask-wearing · COVID-19 · African American · Thematic analysis

Midwest metropolitan cities, like many areas across the nation, experienced a second surge in coronavirus (COVID19) cases during the summer of 2020. Efforts were made to increase compliance with mask-wearing to curtail the rise in high-risk communities. By that time, it was widely accepted that mask-wearing, in combination with social distancing, was the best way to prevent the spread of COVID-19 [1]. African Americans are twice as likely to die from COVID19 or its complications in comparison to Whites and more likely to be hospitalized or experience severe effects [2,3]. The existent disparities are influenced by a multitude of factors, including personal safety behaviors, zip code, profession, healthcare access, discrimination, and health provider bias [4]. African Americans often fill positions that are

Holly J. Jones

joneshj@ucmail.uc.edu

1 College of Nursing, University of Cincinnati, P.O. Box 210038, Cincinnati, OH 45221, USA

2 Greater Cincinnati Chapter, National Black Nurses Association (NBNAGC), Cincinnati, USA considered essential such as those available in healthcare facilities, grocers, gas stations, convenience stores, and restaurants [2]. This is no less true within predominantly African American neighborhoods where the corner market or neighborhood restaurant is easily accessible to obtain items for daily living. These businesses may be owned and operated by people of color.

As the second wave of the virus raged across the nation, there was a renewed effort to increase adherence to social distancing and mask-wearing guidelines supported by local and government health experts. Indeed, prevention is key, yet many neighborhood residents chose not to wear face masks or adhere to social distancing recommendations in public spaces. In doing so, they risked exposure to the coronavirus, transmitting the virus to others, or both [5]. Healthcare experts stressed the importance of personal behaviors in the fight against COVID-19 transmission. Getting the public to 'buy in' on the routine practice of social distancing and mask-wearing was (and continues to be) key to slowing the spread of COVID-19 and protect vulnerable residents [1]. Multiple approaches have been used to re-enforce the 
need for compliance and consistency within the community. Public service announcements and news media often plead with the public to wear masks, avoid crowds, and eliminate nonessential travel, outings, and gatherings. Community leaders and organizations led by example and established community-based working groups to acquire personal protection equipment for distribution. In the state of Ohio, Governor DeWine issued a mandate that masks must be worn in public when social distancing is not possible and when entering businesses [6]. The mandate empowered business owners and employees statewide to require that customers enter their business with a mask; protecting themselves and the surrounding community.

A recent study conducted by an Ohio chapter of the National Black Nurse's Association (NBNA) sought to explore mask-wearing behaviors within African American communities in a large metropolitan city. The study was designed to identify barriers, facilitators, and innovative solutions for mask-wearing in neighborhood businesses with the goal of determining best practices for promoting public mask-wearing during the pandemic. The study took place just after the Ohio mask-wearing mandate was put in place, enabling the local NBNA research team to gather information about behaviors and attitudes before and after the mandate in both essential and nonessential businesses. This report will focus on observed mask-wearing behaviors and responses to the question 'what can make mask-wearing easier for your business and businesses in the neighborhood?'.

\section{Methods}

African American communities were identified based on the research team's historical knowledge of existing communities, residential trends, and census reports. A researcherdeveloped semi-structured interview guide and observational checklist were used to conduct this community-based observational study. In teams of two or more, members of the NBNA research team conducted observations and face-toface interviews with business owners, supervisors, and staff of local businesses in selected African American communities within the metropolitan area. Checklist observations included the type of business, employee and customer maskwearing behaviors, employee tactics to encourage compliance with mask-wearing within the establishment, and signage. The interview guide contained closed and open-ended questions. The scripted interviews elicited information about business policies, provision of masks, employee and customer compliance regarding mask-wearing, and changes in behavior before and after the mandate. Interviewers took notes during the interview to record responses. Immediately following the visit, researchers compiled their data for comparison and completeness.

\section{Data Analysis}

Observational data were analyzed using simple descriptive statistics (count, frequencies, percentages). Narrative data were analyzed using simple content analysis as outlined by Saldana [7]. Quotes were read multiple times for content and understanding. Codes were categorized based on commonalities in the responses and emerging ideas. Themes were identified and agreed upon by the research team.

\section{Findings}

Observations and interviews were conducted for 39 businesses $(\mathrm{N}=39)$ in predominantly African American neighborhoods. Businesses ranged from corner convenience stores, beauty supply, and clothing boutiques to chain stores such as cell phone service providers and corporateowned stores such as grocers. Business owners and their employees reported an increase in mask-wearing by their customers following the institution of the Ohio maskwearing mandate. Some reported difficulty getting customers to comply prior to the mandate, and the mandate provided them with leverage to enforce mask-wearing and social distancing behaviors. There were also reports of reluctance to enforce mask-wearing and social distancing for fear of backlash from customers, such as verbal abuse, anger, or loss of patronage. Differences were noted between independently-owned stores and corporate-owned stores in the neighborhoods. Employees of small, independent stores were more likely to engage with customers and require mask-wearing. Employees of corporate-owned and chain stores were less likely to engage customers regarding mask-wearing, and some referred to corporate policies that prohibited such behavior.

Mask wearing compliance among employees was greater than that noted for customers and mirrored that of management. If the owner or supervising employee was not wearing their mask or wearing it improperly, subordinate employees were frequently noted to mimic that behavior. Interview responses were consistent with behavior and often provided insight into the observed behavior. For example, those who expressed feelings of doubts about the effectiveness of masks or displeasure with the mask-wearing mandate often exhibited poor behaviors such as removing the masks when speaking or not wear them at all. However, when management instituted employee mask-wearing policies, the employees reported adherence at risk of reprimand, regardless of their personal beliefs and attitudes. One woman stated, "The corporation is serious". Employee[s] wear masks and take temperature and stay home if sick". 
When asked, 'What can make mask-wearing easier for your business and businesses in the neighborhood?', “providing free masks" was the most frequent response. Some businesses had masks available for purchase, but many employees expressed the need to offer free masks to customers. Access to masks and availability were viewed as obstacles to compliance. One employee remarked, "Some businesses actually charge and that is absurd". She went on to explain, "... if you talk to people and make them aware of the reasons to wear the masks they understand and comply".

\section{Emerging Themes}

Several themes emerged from the question 'What can make mask-wearing easier for your business and businesses in the neighborhood?'. Themes included 'a sense of community', the 'need for external support', and 'internal leadership' (Table 1). Resident owners of neighborhood businesses expressed pride in their communities; this served as motivation behind the enforcement of mask-wearing in their establishments. When asked what would make mask-wearing easier for his businesses, one owner stated, "Nothing. I know the customers. Most are from the neighborhood. I know their parents." This same owner reported that business was consistent before and after the mask-wearing mandate, despite his requirement that a mask be worn inside. In response to the same question, one supervisor stated, "Consistency. If every store refused to let customers without masks enter, they will comply." Other comments included "working together...if everyone does their part to enforce the rules and “...respect for each other". Others suggested that "[Giving] tips to make wearing the mask more comfortable" was helpful to encourage compliance. Few employees voiced the importance of community if they worked in chain stores or corporate-owned businesses.

A second theme that emerged from responses to the question 'What can make mask-wearing easier for your business and businesses in the neighborhood?' was the need for external support. Business owners expressed frustration with the lack of information and support from local and government organizations. Often the independent business owners and supervisors were unaware of how to obtain personal protection equipment and other supplies. A few stated that

Table 1 Representative responses by theme and type of ownership ( $=39)$

\begin{tabular}{|c|c|c|}
\hline Theme & Corporate $(n=15,40.5 \%)$ & Private $(n=22,59.5 \%)$ \\
\hline \multirow[t]{7}{*}{ 'A sense of community' } & "Providing free masks." & “Educating customers...” \\
\hline & $\begin{array}{l}\text { "Working together...if everyone does their part to } \\
\text { enforce the rules..." }\end{array}$ & $\begin{array}{l}\text { "Nothing. I know the customers. Most are from the } \\
\text { neighborhood... I know their parents." }\end{array}$ \\
\hline & "Provide [masks] when customers do not have one." & $\begin{array}{l}\text { "If you talk to people and make them aware of the rea- } \\
\text { sons to wear the masks they understand and comply." }\end{array}$ \\
\hline & "Work to change people's mindset." & "Send mask to people’s houses." \\
\hline & $\begin{array}{l}\text { "[Produce] masks made with more breathable mate- } \\
\text { rial." }\end{array}$ & $\begin{array}{l}\text { “...Providing masks for free. Some businesses actually } \\
\text { charge and that is absurd...” }\end{array}$ \\
\hline & & $\begin{array}{l}\text { "[Giving] tips to make wearing the mask more comfort- } \\
\text { able." }\end{array}$ \\
\hline & & "Respect for each other" \\
\hline \multirow[t]{5}{*}{ "Need for external support" } & $\begin{array}{l}\text { "...If the police would monitor...[all] the responsibility } \\
\text { falls on the management." }\end{array}$ & $\begin{array}{l}\text { "Consistency. If every store refused to let customers } \\
\text { without masks enter, they will comply.” }\end{array}$ \\
\hline & $\begin{array}{l}\text { “..Authorities having/making [masks] available to give } \\
\text { out." }\end{array}$ & $\begin{array}{l}\text { "Teamwork between the city and small businesses would } \\
\text { help make things easier." }\end{array}$ \\
\hline & “The [Ohio Governor's] mandate helped.” & "Free masks" \\
\hline & & “...If the President encouraged mask wearing." \\
\hline & & “Making it mandatory.” \\
\hline \multirow[t]{4}{*}{ 'Internal leadership' } & $\begin{array}{l}\text { "The corporation is serious. Employee [s] wear masks } \\
\text { and take temperature and stay home if sick." }\end{array}$ & $\begin{array}{l}\text { "[We want] help with supplies and increased pay for } \\
\text { increased work.” }\end{array}$ \\
\hline & $\begin{array}{l}\text { "If we had them to give away to customers without } \\
\text { one." }\end{array}$ & “...Just trying to enforce [mask wearing] is difficult." \\
\hline & $\begin{array}{l}\text { "It [mask-wearing] is not required for [us] to enforce } \\
\text { with customers" }\end{array}$ & \\
\hline & $\begin{array}{l}\text { "[Enforcement is]not pushed by the company leader- } \\
\text { ship." }\end{array}$ & \\
\hline \multirow[t]{2}{*}{ Other } & "Sell fashion masks [with matching t-shirts]" & \\
\hline & "Some people like stylish or branded masks." & \\
\hline
\end{tabular}


“...providing masks for free" would improve community compliance, and "authorities having/making [masks] available to give out" would make it easier on customers and employees alike. However, they also acknowledged a need for support to offset additional costs incurred by independent businesses during the pandemic stating "...[all] the responsibility falls on the management." Many agreed that "Teamwork between the city and small businesses would help make things easier." One employee went on to comment that "... help with supplies and increased pay for increased workload..." was needed.

A final theme that emerged from this question was the need for 'internal leadership'. This sentiment was expressed by supervisors and employees, particularly those employed in corporate-owned stores. Many reported a lack of leadership regarding the enforcement of mask-wearing among customers. When asked why they did not enforce the mandate, some employees stated that the issue was "not pushed by the company leadership." Others stated they were discouraged from enforcing mask-wearing among customers both before and after the mandate by upper management. "It is not required for [us] to enforce with customers". There was concern that enforcement might affect revenue or place employees at risk. It was reported that "some customers leave and do not come back when asked to wear a mask. It has affected business." Others reported that COVID19 complicated their jobs and customer interactions. One employee stated, “...just trying to enforce [mask wearing] is difficult".

Observations during the in-person interviews revealed a subtheme to the theme of 'internal leadership', 'role modeling'. As stated above, it was observed that staff behavior mirrored that of owners and supervisors. This observation extended to the customers as owners and supervisors who wore masks were more likely to report enforcing mask-wearing behavior. Indeed, these individuals were able to report details about their customer experience. One supervisor stated, "[we] turn away three customers a day for not having a mask". Modeling of behavior involved not only the act of putting on a mask but also whether the mask was worn properly. If leadership and role modeling for mask-wearing were absent, employees were more likely to wear the mask below the nose, under the chin, or remove the mask when speaking.

\section{Discussion}

Findings from this community-based study identified barriers experienced by neighborhood business owners and employees in the effort to enforce mask-wearing during the COVID-19 pandemic. Differences were noted between independent businesses and corporate-owned businesses.
Business owners with ties to the community and its residents were more likely to encourage and enforce maskwearing behaviors. In contrast, corporate-owned businesses established policies to protect their employees and minimize conflict with customers.

Mask-wearing behaviors also reflected the beliefs and attitudes of the individuals. Adherence to the maskwearing mandate and positioning of the masks were just a couple of ways that people expressed their beliefs. Leadership and role modeling may supersede personal beliefs. Subordinate employees often mirrored the mask-wearing behaviors of their supervisors and employers. Likewise, customers were more likely to wear masks when authority figures were present and demonstrating proper maskwearing behaviors.

Three themes emerged in response to the question 'What can make mask-wearing easier for your business and businesses in the neighborhood?': 'a sense of community', the 'need for external support', and 'internal leadership'. 'A sense of community' was often the motivation behind efforts to enforce mask-wearing in neighborhood businesses. Indeed, the transmission of COVID-19 to employees in these neighborhood businesses could result in store closures affecting the larger community. With that in mind, the need for resources and support of these businesses was expressed in the second theme, the 'need for external support'. Independent business owners and their employees often lacked information of available resources, while corporate-owned stores were more likely to have masks and hand sanitizer available for customers. Independent business owners expressed the desire for greater collaboration and assistance from local government and other organizations to offset costs. Indeed, the Ohio governor's mandate was well received as it provided leverage for enforcement of mask-wearing within neighborhood businesses. Improved outreach to neighborhood businesses is crucial to maintain the health of the community, ease the financial burden of independently owned businesses, and maintain a safe environment in which to conduct everyday activities.

The final theme, 'internal leadership' and its subtheme 'role modeling' were represented both in the interviews and the observations. Customers and employees responded to leadership. This was observed in owner-employee interactions and employee-customers interactions. Leadership and role modeling appeared to overcome individual attitudes and beliefs. Normalizing mask-wearing through government mandates and role modeling cannot be underestimated as strategies to improve preventive behaviors. Furthermore, role modeling by persons of authority from within the community may strengthen the message received by residents. 


\section{Conclusions}

Healthcare experts, along with other governing institutions, agree that mask-wearing is essential to curb the spread of COVID-19 [1]. This is particularly important for communities of color who bear the heaviest burden of the disease. Everyone has a role in the fight against the pandemic. Findings from this small community-based study suggest that businesses in high-risk communities may play a larger role in modeling and re-enforcing the need for mask-wearing. Independent business owners may be more invested in their communities and thus willing to engage customers. Corporate-owned stores may unknowingly support a culture of indifference because upper management is not in tune with the community. Thus, current policies related to COVID-19 may overlook critical stakeholders in the fight against the spread of the disease.

\section{Implications for policy}

Development of policies in collaboration with key stakeholders, especially independent business owners, is recommended. Focusing on high-risk communities may allow government and community organizations to establish collaborations within the community that may lead to sustainable approaches to decrease health disparities. Collaborative planning has the potential to produce creative and relevant strategies as the community leaders and residents are the experts on the behavior and culture within their respective neighborhoods.

Acknowledgement We would like to acknowledge members of the Greater Cincinnati NBNA chapter who contributed to this research.

Author Contributions Dr. Hutchins is responsible for the conception and design of the study from which the data presented originates. All authors were involved in implementation of the study, qualitative analyses, interpretation of the data, and the writing of this manuscript which included editing and approval of the finalized document.

Funding This study was supported by the University of Cincinnati CCTST COVID-19 Critical Community Challenge Grant (C5G) Program.

Data Availability The data that support the findings of this study are available on request from the corresponding author, Dr. Jones. The data are not publicly available due to their containing information that could compromise the privacy of research participants.

Code Availability Not applicable.

\section{Declarations}

Conflict of interest The authors declare that there is no conflict of interest.
Ethical Approval This study was approved by the University of Cincinnati Institutional Review Board (IRB) prior to the start of the study and data collection. A verbal consent was obtained from each interview participant and an information sheet was provided with an overview of the study. Participant names were not recorded. Survey forms and checklists containing business names and locations were stored separately in a locked file cabinet. Data were de-identified and entered into REDCap, a secure, web-based platform designed to support data capture for research studies. Members of the NBNAGC research team wore masks and practiced social distancing in accordance with CDC guidelines and the Ohio mask-wearing mandate while conducting interviews, observations, and other research activities.

Consent to Participate Verbal consent was obtained from participants prior to conducting the survey interviews. An information study sheet was provided.

Consent for Publication Not applicable.

\section{References}

1. Centers for Disease Control and Prevention. (2020). Scientific brief: community use of cloth masks to control the spread of sarscov-2. US Department of Health and Human Services. https:// www.cdc.gov/coronavirus/2019-ncov/more/masking-science-sarscov2.html

2. Cooper, L. et al. (2020). 2020 state of black America: unmasked. John Hopkins Center for Health Equity (Ed.). Retrieved from https://www.healthequityhub.com/center-news-announcementsblog/2020-state-of-black-america-unmasked

3. Neuman, S. (2020, August 13). COVID-19 death rate for black Americans twice that for whites in the coronavirus crises. National Public Radio. https://www.npr.org/sections/coronavirus-live-updat es/2020/08/13/902261618/covid-19-death-rate-for-black-ameri cans-twice-that-for-whites-new-report-says

4. Gaynor, T. S., \& Wilson, M. E. (2020). Social vulnerability and equity: The disproportionate impact of covid-19. Public Administration Review, 80(5), 832-838.

5. Haischer, M. H., et al. (2020). Who is wearing a mask? Gender-, age-, and location-related differences during the covid-19 pandemic. PLoS One, 15(10), e0240785.

6. Ohio.gov. (2020, July 22). Governor DeWine issues statewide mask order, travel warning. The Official Site of Ohio.gov. Retrieved from https://governor.ohio.gov/wps/portal/gov/gover nor/media/news-and-media/covid19-update-07222020\#: :text= Governor\%20DeWine\%20announced\%20that\%20beginning,in\% 20all\%2088\%20Ohio\%20counties.

7. Saldaña, J. M. (2015). The coding manual for qualitative researchers. (3rd ed.). SAGE Publications.

Publisher's Note Springer Nature remains neutral with regard to jurisdictional claims in published maps and institutional affiliations. 